\title{
RANCANG BANGUN MEKANIK ROBOT PHYSIO TERAPY UNTUK PENDERITA KELUMPUHAN PADA LENGAN
}

\author{
Ahmad Yani ${ }^{1)}$ Joni Kasmara ${ }^{2)}$ \\ Jurusan Teknik Mesin Fakultas Teknik Universitas Trunajaya Bontang. ${ }^{1,2)}$ \\ Jl. Jend. A. Yani No. 55 Telp/Faks. (0548) 3035920, 5116443 Bontang - Kaltim \\ Email: yanibima@gmail.com
}

\begin{abstract}
Abstrak : Robot physio terapy adalah merupakan alat bantu dalam kedokteran yang difungsikan untuk membantu memulihkan kembali - organ tubuh penderita kelumpuhan yang diakibatkan kecelakaan atau penyakit strook yang mengakibatkan terjadinya disfungsi motorik pada otak sehingga anggota badan seperti tangan dan kaki tidak dapat digerakan lagi. Terapy fisik (physio terapy) pada pasien biasanya dilakukan secara manual, dengan cara memijit atau menggerakgerakkan sendi, oleh karena itu dibutuhkan tenaga ahli yang selalu mendapingi pasien pada saat terapy. Sehingga membutuhkan banyak tenaga, waktu, dan biaya untuk perawatan.

Jumlah pasien yang kecelakaan atau terkena penyakit strook sangat banyak sehingga dibutuhkan tenaga perawat yang super extra untuk menanggani pasien, untuk mengatasi kendala tersebut maka kita merancang alat bantu physio terapy untuk membantu paramedis dalam menangani terapy pada pasien.
\end{abstract}

Kata Kunci : Physio terapy, Lengan tangan.

\section{PENDAHULUAN}

Terapy fisik (physio terapy) pada pasien biasanya dilakukan secara manual, dengan cara memijit atau menggerak-gerakkan sendi, oleh karena itu dibutuhkan tenaga ahli yang selalu mendapingi pasien pada saat theraphy. Sehingga membutuhkan banyak tenaga, waktu, dan biaya untuk perawatan. Adapun beberapa jenis alat physiotheraphy yang digunakan dalam dunia medis untuk proses penyembuhan kelumpuhan maupun cedera yang dialami oleh lengan bawah dan lengan atas telah banyak diciptakan, Tetapi kebanyakan desain masih rumit, mahal dan dimensi besar sehingga sulit dipindah-pindahkan. (www.thephysioshop.com)

Hal yang mendorong penelitian ini dilakukan adalah minimnya peralatan terapy fisik yang ada di rumah sakit Indonesia dan Minimnya jumlah perawat dibandingkan jumlah pasien yang harus ditangani, sehingga menyebabkan antrian pasien yang panjang dan lama. Dengan adanya kasus seperti ini perlu dirancang Robot physio terapy yang bisa dioperasikan sendiri (atas petunjuk Dokter), portable (mudah dipindahkan), bisa digunakan berbagai umur (adjustable), programmable). Rancangan alat memiliki beberapa aspek yang mendukung fungsi utamanya, antara lain: mudah dioperasikan, aman bagi pasien, ergonomis (humanmachine interface), mudah perawatan, harga relatif murah, tidak mudah rusak, dekoratif.

\section{TINJAUAN PUSTAKA}

Robotika merupakan sebuah teknologi yang merupakan gabungan dari berbagai macam disiplin ilmu. Untuk bisa mengetahui kompleksitas aplikasi dari teknologi ini diperlukan ilmu pengetahuan yang didapat dari berbagai disiplin ilmu. Hingga saat ini telah berkembang tiga generasi robot, dimana generasi pertama adalah robot yang melakukan gerakan secara berulang-ulang dengan perintah yang diprogramkan sebelum mulai dioperasikan. Generasi kedua adalah robot yang dilengkapi sensor dengan program computer sehingga dapat bereaksi terhadap lingkungan. Generasi terakhir adalah robot 
yang dilengkapi dengan sensor-sensor yang beragam untuk identifikasi informasi secara lebih tepat yang kemudian diolah kedalam supercomputer yang mampu mengambil keputusan sendiri dalam menentukan langkah geraknya sehingga sanggup menghadapi permasalahan yang lebih variatif.

Jenis gerakan sendi pada lengan tangan:

1. Meluncur: gerakan satu permukaan pada permukaan lain seperti pada sendi datar.

2. Fleksi: gerakan pengecilan sudut sendi, misalnya melipat siku.

3. Ekstensi : gerakan pembesaran sudut sendi, misalnya meluruskan siku.

4. Abduksi: gerakan bagian tubuh menjauhi garis tengah, misalnya mengangkat lengan ke sisi tubuh.

5. Adduksi : gerkan bagian tubuh menekati garis tengah, misalnya mendekatkan lengan ke sisi tubuh.

6. Pronasi: gerakan rotasi medial lengan bawah dan tangan sehingga telapak tangan menghadap ke belakang

7. Supinasi: gerakan rotasi lateral lengan bawah dan tangan sehingga telapak tangan menghadap ke depan.

8. Rotasi: gerakan bagian tubuh berputar pada sumbu longitudinalnya, misalnya gerakan telapak tangan ke depan dan ke belakang dengan lengan diekstensikan penuh dicapai dengan rotasi pada sendi bahu.

Sirkumduksi: kombinasi fleksi, abduksi, ekstensi, dan adduksi pada satu gerakan, misalnya mengayun lengan yang terekstensi berputar dalam satu lingkaran.

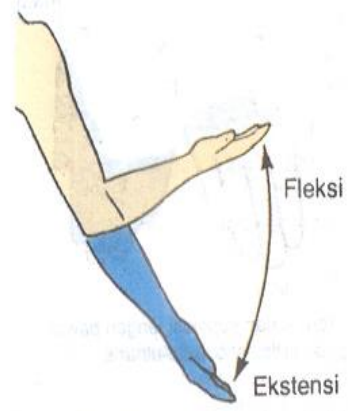

Fleksi dan ekstensi lengan bawah pada sendi siku

Gambar 1 : Gerakan pada lengan tangan

(keith l. moore, Anatomi klinis dasar)

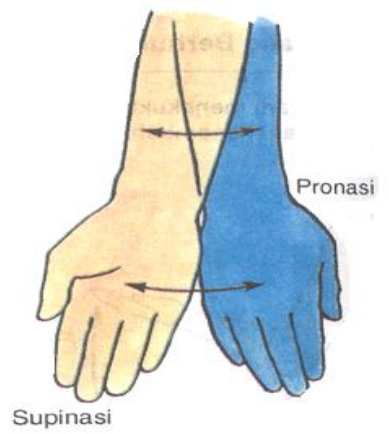

Gambar 2: Gerakan pada lengan tangan

(keith l. moore, Anatomi klinis dasar)

Untuk sudut maksimum gerakan pada bagian-bagian tubuh terutama tangan untuk gerak rotasi lengan bawah maksimum $180^{\circ}$ sedang untuk gerak vertikalnya maksimum $150^{\circ}$

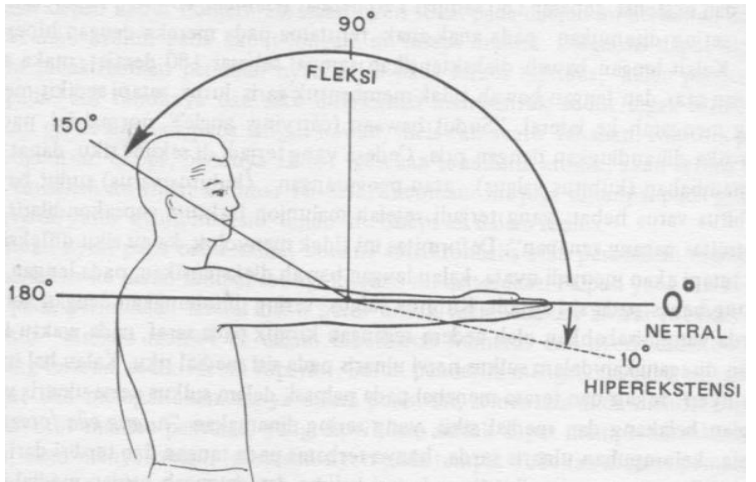

Gambar 3: Gerakan siku pada lengan tangan. (keith l. moore, Anatomi klinis dasar) 


\section{Prinsip Dasar Dinamika}

Secara umum dinamika menyangkut gayagaya yang bekerja pada benda-benda bergerak dengan menggunallkan istilahistilah "usaha, energy,dan daya. Yang terpenting dari pada kuantitas dinamika dan satuan satuanya adalah ;

$>$ massa $m$ adalah kuantitas dasar

\section{Gaya (gaya grafitasi) $\quad F$}

Gaya $F$ adalah hasil perkalian massa mdengan percepatan a

$$
F=m \cdot a
$$

Gaya grafitasi $\mathrm{W}$ adalah gaya yang bekerja pada suatu massa $m$ karna adanya percepatan bumi g;

\section{Usaha W}

$$
\mathrm{W}=\mathrm{m} \cdot \mathrm{g}
$$

Usaha mekanis adalah hasil perkalian gaya $F$ dengan jarak $s$.

Dimana gaya konstan $F$ bekerja pada sebuah benda dalam gerakan linier ke suatu arah yang sejajar dengan jangkauan jarak $s$

$$
W=F . s
$$

\section{Daya $P$}

Daya $\mathrm{P}$ adalah kelanjutan usaha yang berkaitan dengan waktu. Apabila usaha (energi) meningkat atau menurun secara linier dengan waktu, maka daya adalah hasil pembagian usaha dengan waktu.

$$
P=W / t
$$

Untuk gerak melingkar beraturan maka

$$
P=F .2 . \pi . r . n
$$

Dalam persamaan ini kita temukan $F$. $r$,bahwa sama dengan momen $M$ sehingga dapat ditulis :

$$
P=M .2 . \pi . n
$$

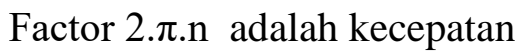
sudut $\omega$ sehingga dapat ditulis

$$
P=M . \omega
$$

\section{METODE PENELITIAN}

\section{Tempat dan Waktu Penelitian}

Penelitian ini dilaksanakan di Laboratorium Teknik Mesin Fakultas Teknik Universitas Muhammadiyah Malang dan waktu penelitian mulai bulan Januari sampai Mei 2009.

\section{Variabel Penelitian}

1. Variabel Bebas: Panjang alat (rangka lengan atas): $1000 \mathrm{~mm}$ dan Lebar alat (rangka lengan atas): $220 \mathrm{~mm}$, Panjang alat (rangka lengan bawah): $500 \mathrm{~mm}$ dan Lebar alat (rangka lengan bawah): 120 $\mathrm{mm}$. Jarak sumbu lengan bawah dengan penyangganya: $45 \mathrm{~mm}$,

2. Variabel terikat: desain alat dan daya motor penggerak.

3. Variabel kontrol: Derajat maksimum putaran $90^{\circ}$ untuk gerak rotasi (Dari data medis), Derajat maksimum putaran $90^{\circ}$ untuk gerak Elevation-Depression ((Dari data medis)

\section{Alat dan Bahan Penelitian}

Alat dan bahan yang digunakan dalam penelitian:

Motor DC berjumlah 4 unit.

Roda gigi, besi plat siku berlubang, poros berulir, pully, V-belt, baut, mur dan Rell penyangga lengan bawah.

\section{Instalasi Alat Penelitian}

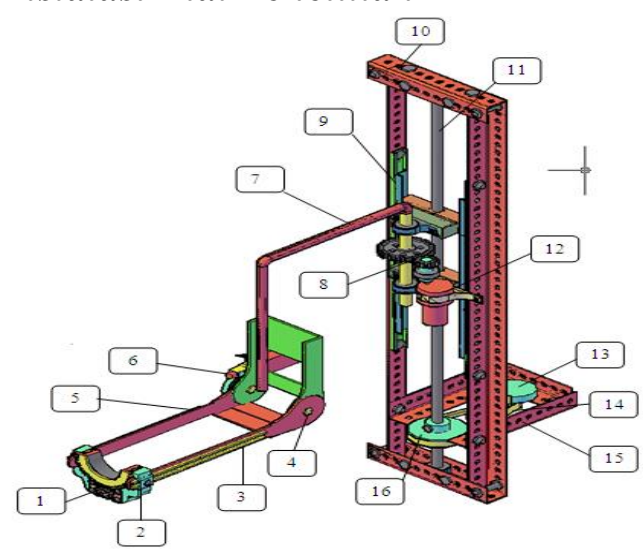

Gambar 4. Instalasi Penelitin. 


\section{Keterangan gambar instalasi penelitian}

1. Roda gigi penggerak pergelangan

2. Penyangga lengan dalam

3. Rell penyangga lengan bawah

4. Poros lengan bawah

5. Rangka lengan bawah

6. Motor penggerak lengan siku

7. Poros penyambung antara lengan atas dan lengan bawah

8. Motor penggerak lengan atas rotasi

9. Rell lengan atas

10. Rangka lengan atas

11. Poros berulir

12. Motor penggerak lengan atas rotasi

13. Motor penggerak lengan atas vertikal

14. V-Belt

15. Rangka penyangga motor

16. Pully

\section{Prosedur Penelitian}

1. Mendesain alat physio terapy sesuai dengan data medis gerakan lengan tangan.

2. Menyiapkan semua bahan dan peralatan yang dibutuhkan.

3. Membuat prototype alat physio terapy.

4. Mencoba alat physio terapy dengan menggunakan motor dan battery sebagai penggeraknya.

5. Menarik kesimpulan dari hasil penelitian yang dilakukan.

\section{Sistem Kerja Robot}

Gerak utama dari alat ini adalah berdasarkan putaran motor. Untuk motor yang pertama yaitu berfungsi menggerakan pergelangan (gerak pronasi dan supinasi). putaran motor dihubungkan oleh poros ke roda gigi 1 kemudian memutar roda gigi 2 yang disambung pada penyangga lengan dalam, Sehingga bagian ini berputar sesuai dengan kemiringan yang diinginkan tetapi penyangga luarnya tetap diam. Sedangkan untuk Motor yang kedua yang bersumbu diporos (siku lengan) berfungsi menggerakkan rangka yang telah dirangkai dengan penyangga lengan dalam, dan luar, serta roda gigi yang di sambung dengan baut pengunci sehingga bergerak vertical naik turun ( gerak Fleksi dan Ekstensi) sesuai dengan kemiringan sudut yang diinginkan.

Untuk motor yang ketiga putaran motor di hubungkan oleh poros ke roda gigi 1 kemudian memutar roda gigi 2 yang disambung pada poros transmisi sehingga bagian poros ini berputar sesuai dengan sudut yang diinginkan (gerak horizontal). Sedangkan motor yang ke empat bergerak dengan melaluli sabuk dan pully sebagai reduksi untuk memutar poros ulir yang telah dirangakai dengan rangka rel, rangka poros transmisi serta yang di sambung dengan poros ulir sehingga bergerak vertical naik turun sesuai dengan batas yang diinginkan.

\section{HASIL DAN PEMBAHASAN}

Pada perancangan dan pembuatan alat ini mekanismenya harus diperhitungkan agar bisa menentukan ukuran yang ditetapkan sebagai desain dari perancangan sehingga ukuran-ukuran yang ada kuat dan aman untuk pemakainya.

\section{Data Perencanaan Lengan bawah}

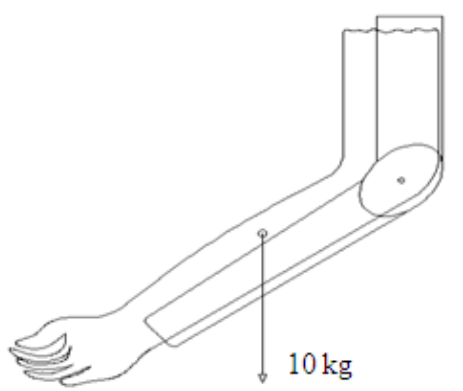

- Beban maksimum lengan bawah + Resistensi dari otot-otot struktur:10 $\mathrm{Kg}$

- Jarak sumbu lengan dengan penyangganya: $45 \mathrm{~mm}$

- Panjang alat: $500 \mathrm{~mm}$

- Lebar alat: $120 \mathrm{~mm}$ 
- Derajat maksimum putaran $150^{\circ}$ untuk gerak fleksi (Dari data medis)

- Derajat maksimum putaran $90^{\circ}$ untuk gerak pronasi (Dari data medis)

- Kecepatan sudut: 8,7222 rad/s

- Percepatan sudut: $2,1805 \mathrm{rad} / \mathrm{s}^{2}$

\section{Data Perencanaan Lengan Atas}

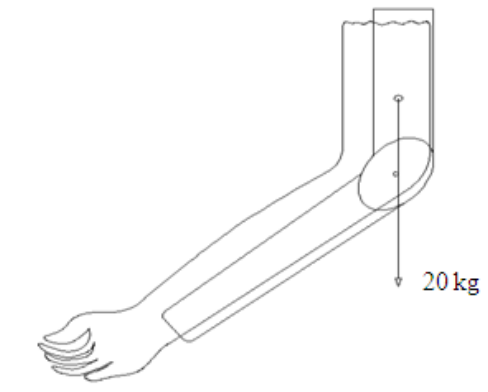

- Beban maksimum lengan atas + Resistensi dari otot-otot struktur : 20 $\mathrm{Kg}$

- Panjang alat : $1000 \mathrm{~mm}$

- Lebar alat : $220 \mathrm{~mm}$

- Derajat maksimum putaran $90^{\circ}$ untuk gerak rotasi (Dari data medis)

- Derajat maksimum putaran $90^{\circ}$ untuk gerak Elevation-Depression ((Dari data medis)

- Kecepatan sudut : 8,7222 rad/s

- Percepatan sudut : 2,1805 $\mathrm{rad} / \mathrm{s}^{2}$

Gaya yang terjadi dan Daya yang diperlukan pada sistem.

\section{a. Motor Satu}

Pada system yang ke petamay ini diambil pada kondisi $90^{\circ}$

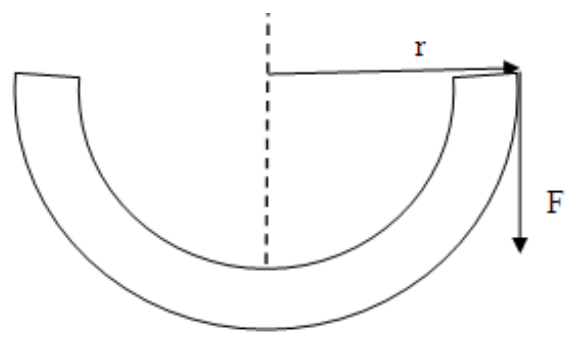

Karena $\quad \mathrm{I}=f \mathrm{dm} . \mathrm{r}^{2}$

(A.R. Holowenko: Dinamika permesinan)

$$
\begin{aligned}
& =\mathrm{r}^{2} f \mathrm{dm} \\
& =\mathrm{r}^{2} \cdot \mathrm{m} \\
& =0,062^{2} \cdot 5 \\
& =0,0192 \mathrm{~kg} \cdot \mathrm{m}^{2}
\end{aligned}
$$

Maka torsi yang didapat adalah :

$$
\mathrm{T}=\mathrm{I} . \alpha
$$

(A.R. Holowenko Dinamika permesinan)

$$
\begin{aligned}
& =0,0192 \times 2,1805 \\
& =0,042 \mathrm{~N} \cdot \mathrm{m}
\end{aligned}
$$

\section{Daya yang diperlukan}

Dari hasil yang diperoleh maka Daya yang dibutuhkan untuk motor satu sebesar:

$$
\begin{aligned}
\mathrm{P} & =\mathrm{T} . \omega \\
& =0,042 \times 8,7222 \\
& =0,3663 \text { Watt. }
\end{aligned}
$$

Maka daya motor yang dipilih untuk gerak rotasi pada sendi siku sebesar 5 Watt.

\section{b. Motor kedua}

Pada sistem yang ke dua ini diambil pada kondisi $90^{\circ}$

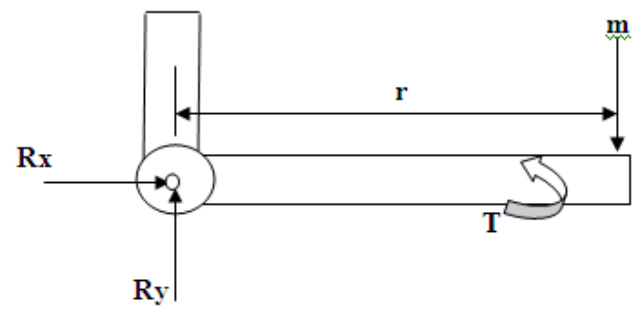

$$
\text { Karena } \mathrm{I}=f \mathrm{dm} . \mathrm{r}^{2}
$$

(A.R. Holowenko: Dinamika permesinan)

$$
\begin{aligned}
& =r^{2} f \mathrm{dm} \\
& =\mathrm{r}^{2} \cdot \mathrm{m} \\
& =0,4^{2} \cdot 10 \\
& =1,6 \mathrm{~kg} \cdot \mathrm{m}^{2}
\end{aligned}
$$

Maka torsi yang didapat adalah :$$
\mathrm{T}=\mathrm{I} . \alpha
$$

(A.R. Holowenko: Dinamika permesinan)

$$
\begin{aligned}
& =1,6 \times 2,1805 \\
& =3,4888 \text { N.m }
\end{aligned}
$$


Daya yang diperlukan

Dari hasil yang diperoleh maka Daya yang dibutuhkan untuk motor satu sebesar:

$\mathrm{P}=\mathrm{T} . \omega$

$$
\begin{gathered}
=3,4888 \times 8,7222 \\
=30,4300 \text { Watt. }
\end{gathered}
$$

Maka daya motor yang dipilih untuk gerak rotasi pada sendi siku sebesar 40 Watt.

\section{c. Motor Ketiga}

$$
\text { Karena } \mathrm{I}=f \mathrm{dm} \cdot \mathrm{r}^{2}
$$

(A.R.Holowenko:Dinamika permesinan)

$$
\begin{aligned}
& =\mathrm{r}^{2} f \mathrm{dm} \\
& =\mathrm{r}^{2} \cdot \mathrm{m} \\
& =0,4^{2} \cdot 15 \\
& =2,4 \mathrm{~kg} \cdot \mathrm{m}^{2}
\end{aligned}
$$

Maka torsi yang didapat adalah:

$$
\mathrm{T}=\mathrm{I} . \alpha
$$

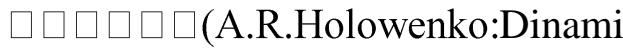
ka permesinan)

$$
\begin{aligned}
& =2,4 \times 2,1805 \\
& =5,2332 \text { N.m }
\end{aligned}
$$

\section{Daya yang diperlukan}

Dari hasil yang diperoleh maka Daya yang dibutuhkan untuk motor ke tiga sebesar:

$$
\begin{aligned}
\mathrm{P} & =\mathrm{T} . \omega \\
& =5,2332 \times 8,7222 \\
& =45,64501 \text { Watt. }
\end{aligned}
$$

Maka daya motor yang di pilih untuk gerak rotasi pada siku sebesar 75 Watt.

\section{d. Motor keempat}

$$
\text { Karena } \mathrm{I}=f \mathrm{dm} . \mathrm{r}^{2}
$$

Holowenko: Dinamika permesinan)

$$
\begin{aligned}
& =\mathrm{r}^{2} f \mathrm{dm} \\
& =\mathrm{r}^{2} \cdot \mathrm{m} \\
& =0,4^{2} \cdot 20 \\
& =3,2 \mathrm{~kg} \cdot \mathrm{m}^{2}
\end{aligned}
$$

Maka torsi yang di dapat adalah :

$$
\mathrm{T}=\mathrm{I} . \alpha
$$

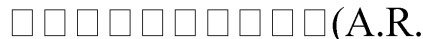

Holowenko: Dinamika permesinan)

$$
\begin{aligned}
& =3,2 \times 2,1805 \\
& =6,9776 \text { N.m }
\end{aligned}
$$

\section{Daya yang diperlukan}

Dari hasil yang diperoleh maka Daya yang dibutuhkan untuk motor ke empat sebesar:

$$
\begin{aligned}
\mathrm{P} & =\mathrm{T} . \omega \\
& =6,9776 \times 8,7222 \\
& =60,8600 \text { Watt. }
\end{aligned}
$$

Maka daya motor yang dipilih untuk gerak rotasi pada siku sebesar 100 Watt.

\section{KESIMPULAN}

Dari hasil penelitian dapat diambil kesimpulan bahwa:

* Secara kinematik, gerakan robot physio terapy (terapy fisik) ini sesuai dengan data medis gerak tulang lengan.

* Untuk gerak Fleksi dan Ekstensi maksimum kemiringan $150^{\circ}$

* Untuk gerak pronasi dan supinasi maksimum kemiringan $90^{\circ}$

* Untuk gerak aduksi dan abduksi( rotasi) maksimum kemiringan $90^{\circ}$

* untuk gerak Elevation dan Depression maksimum kemiringan $90^{\circ}$

* Motor yang digunakan :

Motor pertama : Untuk menggerakan pergelangan

$>$ Jenis Motor : DC Geared Motor

$>$ Daya Motor : 5 Watt

$>$ Tegangan : 24 Volt

Motor kedua : Untuk mengerakan sendi siku $>$ Jenis Motor : DC Geared Motor 
$>$ Daya Motor : 40 Watt

$>$ Tegangan : 24 Volt

Motor ketiga : Untuk menggerakan sendi bahu berputar

$>$ Jenis Motor : DC Geared Motor

$>$ Daya Motor : 75 Watt

$>$ Tegangan : 24 Volt

Motor keempat: Untuk menggerakan sendi bahu vertikal $>$ Jenis Motor : DC Geared Motor

$>$ Daya Motor : 100 Watt

$>$ Tegangan : 24 Volt

\section{DAFTAR PUSTAKA}

A.R. Holowenko, 1996. Dinamika Permesinan, Erlangga Jakarta

ARMin Robot, Patient Cooperative Robot Aided habitation for upper extrimities, 2006, ETH Zurich

Budiono, 2005. Robotika Universitas Muhammadiyah Malang.

Evelyn C. Pearce, Anatomi \& Fisiologi untuk paramedis. Gramedia Jakarta

John gibson, Fisiologi \& anatomi modern untuk perawat. Gramedia Jakarta

Hidayat, R. 2003, Simulasi perhitungan torsi motor penggerak lengan robot 4-Dof Kapasitas 500 GR, Skripsi, UMM

http:// www.thephysioshop.com

keith 1. moore, Anne m. r. agur, Anatomi klinis dasar. Gramedia jakatra
Sularso, Kiyokatsu Suga, 1997. Dasar perencanaan dan pemilihan elemen mesin. Pradya pramita.

Lubos Bernhard, 1995, Terapy appliance for stimulating arm and hand, patent DE4445374, esp@ cenet 